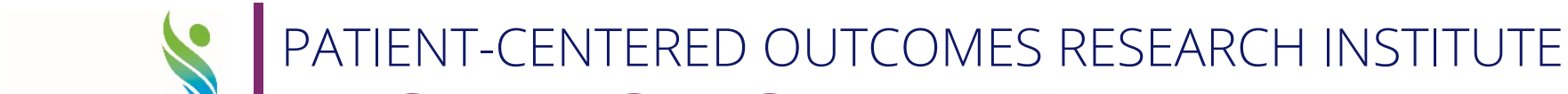 pcori). RESEARCH SUMMARY
}

\section{Testing a Program to Improve Patient- Clinician Communication for Patients Who Speak Limited English}

Principal investigator

Leah S. Karliner, MD, MAS
Organization

University of California San Francisco

\section{What was the research about?}

Compared with fluent English speakers, patients who speak limited English often receive lower quality health care and have worse health. Offering patients a better way to talk about their health in their preferred language may improve health and quality of care.

In this study, the research team compared patients who received care before and after their clinics started using the Language Access Systems Improvement program, or LASI. Before LASI, patients scheduled an in-person interpreter before their clinic visit. Or they could use the phone to talk to an interpreter on demand. When treating patients who spoke limited English, bilingual clinicians spoke in Cantonese, Mandarin, or Spanish based on their own comfort level.

After LASI, patients and clinicians could request ondemand interpreters via video. Clinicians could also take a test to be certified to use a non-English language with patients.

The research team looked at patient-clinician communication and health outcomes for patients who spoke limited English.

\section{What were the results?}

During clinical visits where clinicians and patients didn't speak the same language, after LASI, patients were more likely to
- Use an interpreter

- Discuss exercise

- Remember discussing exercise and diet

- Complete lab tests within 30 days

LASI didn't change whether patients

- Had a new prescription from their clinicians

- Knew if clinicians prescribed a new medicine

- $\quad$ Discussed diet during the visit

- Completed lab tests within 100 days

- Visited a referred specialist

- Had better control of their blood pressure, heart disease, or diabetes

\section{Who was in the study?}

To look at patient-clinician communication, the study included 1,029 clinic visits with adults at least 40 years old. All received care at a primary care practice in San Francisco, California. Of these adults, 73 percent were Chinese, and 27 percent were Latino. The average age was 70, and 67 percent were women.

To look at health outcomes, the study included 2,123 adults. All had at least one chronic health 
problem. Of these adults, 59 percent were Chinese, and 41 percent were Latino. The average age was 64 , and 57 percent were women.

\section{What did the research team do?}

The research team surveyed patients by phone to ask about patient-clinician communication one week after their clinic visit. The team also looked at health records before and after LASI.

Patients and caregivers gave input on the study.

\section{What were the limits of the study?}

This study took place in one practice in one city. Findings may differ in other places.

Future research could look at more ways to improve health and health care for patients who speak limited English.

\section{How can people use the results?}

Health systems can use the results when looking at ways to support patients who speak limited English.

To learn more about this project, visit www.pcori.org/Karliner337. 